\title{
THE DISTRIBUTION OF SUMMER SHOWERS OVER SMALL AREAS
}

\author{
OBIE Y. CAUSEY \\ Weather Bureau Airport Station, Atlanta, Ga. \\ [Manuscript received January 2, 1953; revised May 4, 1953]
}

\begin{abstract}
The spatial scattering of summer showers over much of the United States presents many problems to the forecasters. The primary purpose of this investigation is to determine the areal distribution, during 24-hour periods, of the occurrence of summer rains over three small areas. The areas selected for study are located near Lincoln, Nebr., Peoria, Ill., and in east central Ohio and are defined by circles of radii of about 35 miles. Precipitation data are taken mostly from the records of cooperative stations over a period of 4 to 6 years, depending upon available records. The analyses of these data are compared with a similar analysis of data for the Atlanta area [1] and it is found that there is little difference between the scattering of summer showers over the Southeast and over the three more northerly areas.
\end{abstract}

\section{INTRODUCTION}

Summer rains over much of the United States occur mainly in the form of showers. The average summer rainfall over a period of years changes but little over short distances, where there are unimportant topographic differences, but, on the other hand, it is well known that amounts or occurrences vary greatly within a few miles during periods or days of summer showers. For this reason, the term "scattered" is often used by forecasters to describe the expected shower distribution during specific periods or days. Shower forecast terminology has been receiving more and more attention during recent years, but research on the areal distribution of summer rain during particular days or periods has been limited. An attempt has been made in the Southeast to establish a forecast terminology containing terms which indicate, in effect, the forecaster's estimate of the probability of rain in any particular spot, such as on any given farm. It has been assumed that if the distribution of showers on any given day is more or less random, the probability of a shower at a given location will be indicated by the number of points within an area of reasonable size that actually get rain. This may or may not be a valid assumption. Furthermore, the exact size of an area of "reasonable size" and the optimum spacing of observing stations are open to question. It is beyond the scope of this paper to discuss either of these points. Nevertheless, it would be desirable to establish a shower terminology that would apply to the whole country, or at least to the area between the Rocky Mountains and the Appalachians. For this purpose it would be desirable to make studies similar to [1] covering, in sufficient detail, the whole country, or at least the area just mentioned. It is the purpose of the present work to make, at the suggestion of the Atlanta Research Forecaster, such a study for three small areas located in more northerly latitudes and to compare the results with those obtained by Beebe [1] for the Atlanta, Ga., area. The amount of time available makes it impossible at present to extend the study to cover additional small areas. Moreover, the necessity for making such an extension does not appear to be as great, considering the results of this study, as would be the case if large geographical differences in shower distribution had been found. It is hoped that the data presented herein will give some indication of the practicability of adopting a standard shower-forecast terminology, or at least provide some background for further study.

\section{SELECTION OF AREAS AND DATA}

This study is patterned after a previous work [1] except that in the present study the sizes of the areas and number of stations in each area were reduced by one-half. Examination of the distribution of precipitation-reporting stations [2] over several States along the 40th parallel and between the Rocky Mountains and the Appalachians suggested three small areas for study. These are located near Lincoln, Nebr., Peoria, Ill., and in east central Ohio, and are defined by circles of radii of about 35 miles. In determining the spatial distribution of summer rains, it would be desirable to use only rain periods or assign each shower or rain at each station to a particular date. However, data and time limitations preclude such a refined determination of shower distribution. A rain day here is defined as a date during which measurable rain is recorded during a 24-hour period. It would be desirable in this study to end the 24-hour period near the time of the minimum frequency of occurrence in order to minimize the number of apparent rain days due to the occurrence of rain from 1 shower during 2 consecutive 24-hour periods. At Atlanta, the frequency distribution of hourly occur- 
rences shows a decided minimum about mid-morning and stations were selected for use in that study which measured 24-hour precipitation amounts around 0700 EST. It was not possible to select the reporting stations for the present study entirely on such a basis because not enough stations in these areas made observations at the proper times. Instead, the selections had to be based upon the greatest number of stations, within a particular area, that reported at about the same time. It was found that only 20 stations in each area could be utilized and even with this limited number it was necessary in some cases to use data from a few stations at which the observation time differed by about 6 hours. The lengths of record used for the study varied between 4 summer seasons for the Peoria area (1948-51) and 6 seasons for the Lincoln area (194651). More data were not readily available. There were occasional periods during which the record from a station was missing and data from some nearby station not included among the 20 were substituted.

\section{RESULTS FOR THE PEORIA AREA}

The 20 stations that were selected in the Peoria area reported 24-hour precipitation amounts ending near 1800 local time. The information readily available regarding the hourly frequency distribution of rain occurrences in this area and for this season was inadequate to establish with certainty the time of minimum frequency. However, the frequency distribution of hourly occurrences for three stations in the area, the Weather Bureau Airport Station in Peoria, Peoria Lock and Dam, and Princeton, showed a minimum near 2000 CST during the period studied (1948-51). Assuming this indicated minimum is representative of the area, the use of 24-hour precipitation measurements ending at $1800 \mathrm{CST}$ will result in a near minimum of unreal or apparent rain occurrences due to rain continuing into the next period. The total rainfall for each station on each day was tabulated for the four summer (June, July, and August) seasons, 1949 through 1951.

This area covers about 4,000 square miles and observations from 20 stations were used to determine the distribution over the area. If a station density of one per 200 square miles is adequate to describe the distribution of showers, each individual shower must, on the average, cover at least this much area during its life cycle. Some evidence that this is true is shown by the total rainfall associated with several individual thunderstorms in Ohio [3] where the measurable rainfall extended over areas of from about 150 to 250 square miles. Additional evidence on the adequacy of this station density is shown in figure 1 where the number of stations used to represent an area $(1,5,10,15$, or 20$)$ is plotted against the percentage of days during which at least one station within the appropriate group reported rain. For example, if one station, Peoria, is used to represent the area, rain was reported on about 29 percent of all days. This compares with about 30 percent over a $47-$ year record. In using 5 stations ${ }_{\text {ie }}$ to represent

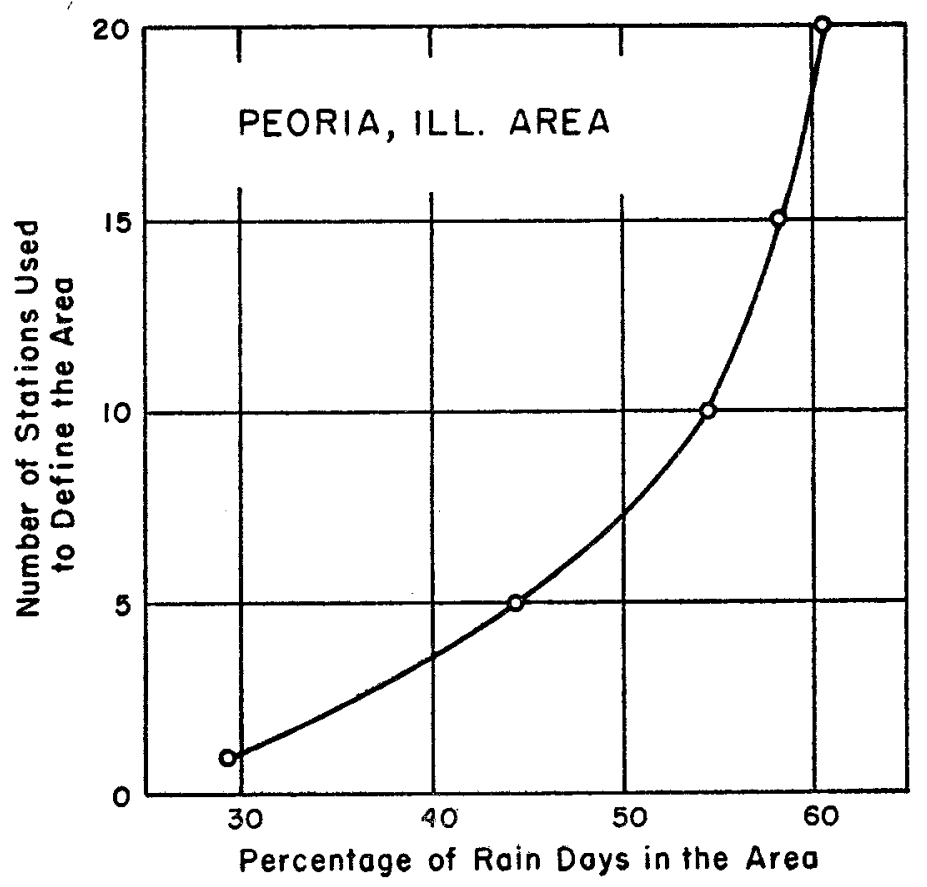

Figure 1.-Dlagram showing the percentage of days when at least 1 station within a group of $1,5,10,15$, or 20 stations reported rain. Data are from the Peoria, Ill., area and are for the four summer seasons, 1948-51.

the area, it was found that at least 1 of these stations reported rain on 44 percent of all days. The station density was then increased to include these 5 stations plus 5 more to make 10 , and then repeated for 15 and finally for all 20 stations. A smooth curve was fitted to these points by eye and it may be noted that between 15 and 20 stations the curve approaches independence of the abscissa. Thus, the precipitation data from these 20 stations provide a reasonably good indication of the precipitation coverage.

These data were then summarized to show the total number of days during which no station reported rain, any 1 station of the 20 reported rain, any 2 stations of the 20 reported rain, etc., through all 20 stations. A cumulative total, converted to percent of all days, was made, starting with rain at no station and on through 20 stations (100 percent). These data were plotted on figure 2 and a smooth curve (broken line) was fitted by eye. Only the curve itself is shown here in order that a comparison may be made between the various areas. It is interesting to note the difference between the curve based upon the data from 20 stations in the Atlanta area and that for the Peoria area. In the Peoria area there are about 10 percent more days when no station reported rain and about 3 percent more days when 20 stations reported rain. On only 54 percent of the days in the Peoria area is there some scattering (rain at at least 1 station but not all 20) of showers as compared with 67 percent of all days in the Atlanta area. This apparent difference of scattering between the two areas, amounting to 13 percent of all days, is largely accounted for by the difference in the frequency of rain in the two areas, rather than by any difference in the distribution of occurrences. That is, on only 29 percent of all days in the Atlanta area was no rain observed 


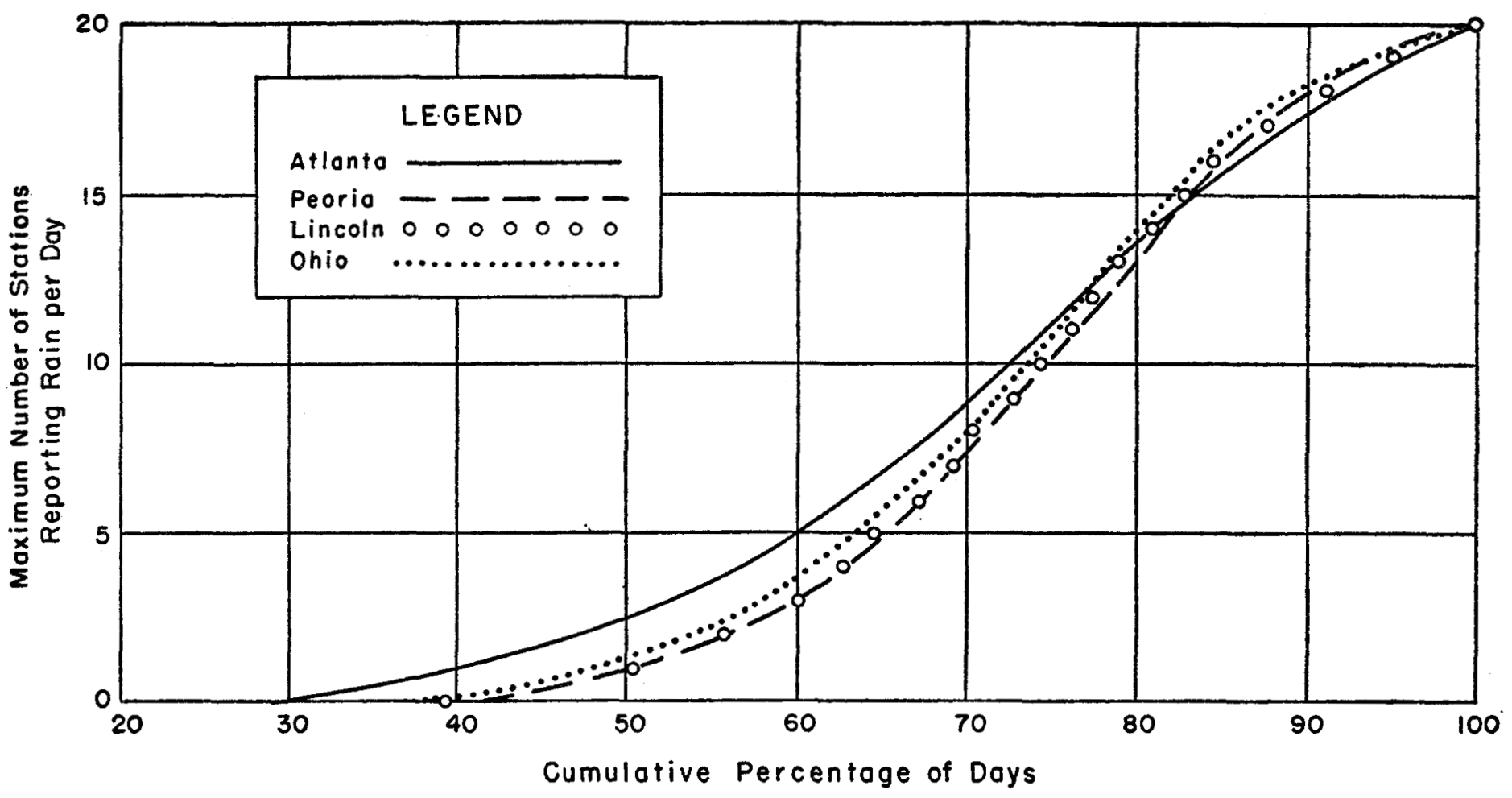

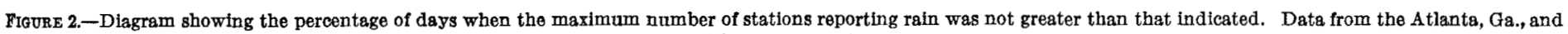

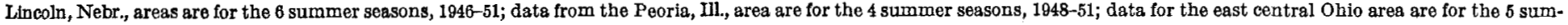
mer seasons, 1948-52.

as compared to 39 percent of all days in the Peoria area, which accounts for 10 percent of the 13 percent difference in apparent total scattering.

\section{RESULTS FOR THE LINCOLN AREA}

The diurnal frequency distribution of summer rainfall occurrences in the Lincoln area [4] shows a minimum shortly after noon with a gradual increase to a maximum soon after midnight. Available reports made it necessary to select stations for this study that reported around 1900 CST so that there will be more days during which rain was reported than there were rain periods. In addition, the two Weather Bureau stations at Lincoln reported 24-hour amounts ending at midnight (near maximum frequency of occurrence) so that a time lag is also introduced. These factors tend to indicate more scattering of showers than actually occurs.

Data were used for six summer seasons, 1946 through 1951 , and they were summarized as in the case of the data for the Peoria area. A curve for the Lincoln data is not shown in figure 1, for these data gave a curve nearly identical to that for the Peoria area. Moreover, the Lincoln data for figure 2 are so similar to those for the Peoria area it was impracticable to show both curves in the same figure. Therefore, only the plotted points (crosses) for the Lincoln data are shown in figure 2. There is obviously no significant difference in the scattering of showers between this and the Peoria area.

\section{RESULTS FOR THE EAST CENTRAL OHIO AREA}

The hourly frequency of summer rain in central Ohio was found by Martin [5] to be at a minimum around 0400 and at a maximum around 1800 local time. Thus, of those available, the 0700 observations are the most desirable for this study while the midnight observations would introduce more apparent rain occurrences. It appeared impossible to find an area in Ohio where there was a good concentration of stations reporting at the same time of day, as was true of the Peoria area. The best concentration provided data from 20 stations with measurements around 0700 for three seasons (1950-52), and these 20 stations were selected for use in this study. In order to increase the amount of data, these 20 stations or substitutions were used for an additional two seasons (1948-49). During the 1949 season, substitute stations with measurements around 0700 were used on about onethird of the days; and during the 1948 season, substitute stations were used on about one-half of the days including three stations with midnight observations. In addition, it was necessary to substitute stations that were located a little outside the 35 -mile radius in a few cases. These factors will introduce some error in the data and indicate scattering of showers that does not exist. However, these data at least provide some approximation of the areal coverage. The curve for this area is not shown in figure 1 because, as in the case of the Lincoln area, it is nearly identical to the curve for the Peoria area. The 
data were summarized and plotted on figure 2 but only the curve itself (dotted line) is reproduced here. This curve indicates about the same scattering of showers as the Peoria and Lincoln data and not quite as much scattering as the Atlanta data.

\section{CONCLUSIONS}

As indicated by figure 2, the percentage of all days when some scattering of rain occurs (rain at at least 1 but not all stations) is somewhat larger for the Atlanta area than it is for the 3 other areas. These percentages are 67 for the Atlanta area, 54 for the Peoria area, 55 for the Ohio area, and 56 for the Lincoln area. However, as indicated in the discussion of Peoria data, nearly all of the difference is accounted for by the difference in percentage of time when no station in the area observed rain. Any difference between areas in the distribution of areal coverage of showers on days when showers occur would be indicated in figure 2 by differing shapes of the curves. If there were no scatter, that is, if rain occurred at all stations every time it occurred at a single station (e. g., at Atlanta) the difference in cumulative percentage of days when a maximum of 19 stations reported rain and when no station reported rain would be zero. In this case the Atlanta curve would be a straight line running along the 66 percent line from zero through 19 stations and then to the point for 100 percent and 20 stations. The "noscatter" curve for the Peoria area would run along the 71 percent line, that for the Lincoln area along the 68 percent line, and for the Ohio area along the 68 percent line. The deviation of the actual curve from the curve for "no-scatter" is one measure of the amount of scattering, and any tendency for the actual curve to approach the shape of the "no-scatter" curve indicates deviation from perfectly random scattering. Considering the "no- scatter" curves for all areas and the shapes of the actual curves it is obvious that ( 1 ) showers occur in the Atlanta area on 9 to 10 percent more days than they occur in the other three areas, (2) there is little difference in the randomness of the distribution between the four areas when rain does occur. This latter conclusion was further verified by drawing curves similar to those in figure 2 using percent of rain days rather than percent of all days.

In view of these conclusions, there would appear to be no significant reason for not using the same shower forecast terminology for all areas studied, insofar as the distribution of showers is concerned.

\section{ACKNOWLEDGMENT}

The author wishes to thank Mr. Robert G. Beebe and Mr. John C. Ballard for their valuable assistance throughout this study.

\section{REFERENCES}

1. Robert G. Beebe, "The Distribution of Summer Showers Over a Small Area," Monthly Weather Review, vol. 80, No. 6, June 1952, pp. 95-98.

2. U. S. Weather Bureau, Climatological Data for the United States, Parts I and II, summer months, 1946-52.

3. Horace R. Byers and Roscoe R. Braham, Jr., The Thunderstorm, U. S. Weather Bureau, Washington, D. C., June 1949, pp. 61, 63, 210-234.

4. H. G. Carter, "Variations in Hourly Rainfall at Lincoln, Nebr.," Monthly Weather Review, vol. 52, No. 4, April 1924, pp. 208-212.

5. H. H. Martin, "Hourly Frequency of Precipitation in Central Ohio and Its Relation to Agricultural Pursuits," Monthly Weather Review, vol. 46, No. 8, August 1918, pp. 375-376. 